\title{
PREPARATION OF HIGH DILATABILITY EXPANDABLE GRAPHITE AND ITS FLAME RETARDANCY FOR LLDPE
}

\author{
X. Y. PANG* M. K. SONG Y.TIAN M.W.DUAN \\ College of Chemistry and Environmental Science, Hebei University, Baoding 071002 People' Republic of China
}

(Received: March 1, 2012 - Accepted: June 12, 2012)

\begin{abstract}
To prepare expandable graphite (EG) with high anti-flame property for Linear low density polyethylene (LLDPE), dosages of oxidant $\mathrm{KMnO}_{4}$, intercalation reagent $\mathrm{H}_{2} \mathrm{SO}_{4}$ and ancillary intercalation reagent $\mathrm{Na}_{4} \mathrm{P}_{2} \mathrm{O}_{7}$ were optimized during oxidation intercalation reaction of natural graphite. EG with an initiation expansion temperature of $148 \pm 2{ }^{\circ} \mathrm{C}$ and expansion volume of $550 \mathrm{~mL} / \mathrm{g}$ can be prepared according to the mass ratio of $\mathrm{C}: \mathrm{KMnO}_{4}: \mathrm{H}_{2} \mathrm{SO}_{4}(98 \%): \mathrm{Na}_{4} \mathrm{P}_{2} \mathrm{O}_{7}=$ 1.0:0.4:5.0:0.6 $\left(\mathrm{H}_{2} \mathrm{SO}_{4}\right.$ should be diluted to the mass concentration of $80 \%$ before intercalation reaction), the reaction time is 40 min at constant $40{ }^{\circ} \mathrm{C}$. Addition of $30 \%$ of the prepared EG to LLDPE can improve its limiting oxygen index LOI from $17.5 \%$ to $29.4 \%$, and the synergistic anti-flame LOI of $20 \%$ EG with 10 polyphosphate (APP II) can reach to $31.2 \%$. TG and DTA analysis were completed to discuss the anti-flame mechanism. $70 \% \mathrm{LLDPE} / 10 \% \mathrm{APP}(\mathrm{II}) / 20 \% \mathrm{EG}$ synergistic anti-flame system can cause higher residual carbon and lower material surface temperature.
\end{abstract}

Key words: Expandable graphite, Dilatability, Sodium pyrophosphate, Flame retardancy, LLDPE, Mechanism

\section{INTRODUCTION}

It's the drawbacks of lower oxygen index, flammability, fusion and dripping that limit the extensive use of Polyethylene $\mathrm{PE}^{1,2}$. So flame retardant FR additives are needed, among which halogenated compounds are the most widely used, and brominated additives are the main fire retardants $\mathrm{FR}^{3}$. But during the combustion of flame retarding polymer based on these retardants, halogen acids are evolved ${ }^{4}$, people would be exposed to these irritants and potential corrosion damage to equipment would occur ${ }^{5}$. So much work has been done on halogen-free FRs. Intumescent additives ${ }^{6}$ provide a effectively way to impact burning performance of polymeric materials. Once exposed to a heat source ${ }^{7}$, intumescent systems develop a voluminous, stable carbonaceous layer on the surface of the material. This layer limits heat and mass transfer, as well as oxygen diffusion, between the heat source and the polymer thus interrupting the self-sustained combustion of the polymer.

Expandable graphite EG is prepared when non-carbonaceous reactants are inserted into the layers of graphite through chemical or electrochemical reaction ${ }^{8,9}$. When EG is heated, it will become expanded graphite with porous structure and high expanded volume ${ }^{10}$. So EG is a good intumescent type flame-retardant for its good capability of halogen-free, non-dropping, lowsmoke and low pollution potential ${ }^{11,12}$.

The anti-flame mechanisms of EG might be explained as: 1. when EG exposes to flame, it gives a swollen multicellular char, which may protect materials from the heat of combustion, limit the access of oxygen to the polymer, and reduce the production of smoke, so it is capable of protecting the underlying material from the action of the flame. 2. During the instant expansion of EG, it absorbs huge heat, which can decrease the burning temperature. 3 . At high temperatures, EG gets oxidized on reaction with $\mathrm{H}_{2} \mathrm{SO}_{4}$ (equation 1). The evolved gases cause the expansion of the material; this expanded volume suffocates the flame and acts as physical barrier for heat and mass transfer.

$$
\mathrm{C}+2 \mathrm{H}_{2} \mathrm{SO}_{4} \rightarrow \mathrm{CO}_{2} \uparrow+2 \mathrm{H}_{2} \mathrm{O} \uparrow+2 \mathrm{SO}_{2} \uparrow
$$

Both initiation expansion temperature and expansion volume EV are two important characteristics of $E G^{13}$. If its initiation expansion temperature is lower than materials' machining temperature, it will decompose during material machining, then cause void flame retardancy. While, too high initiation expansion temperature will cause EG doesn't work in the flaming early stage. In the preparation of EG, its initiation expansion temperature and expansion volume are affected by oxidant, intercalation reagent, ancillary intercalation reagent, reaction time and reaction temperature. Wang ${ }^{14}$ prepared an EG with an initiation expansion temperature of $130^{\circ} \mathrm{C}$ and expansion volume of 350 $\mathrm{mL} / \mathrm{g}$ through $\mathrm{HNO}_{3} / \mathrm{HBrO}_{3} / \mathrm{KMnO}_{4}$ oxidation intercalation system. With $85 \%$ $\mathrm{H}_{2} \mathrm{SO}_{4}$ as inserting reagent and $\mathrm{KMnO}_{4}$ as oxidant, through oxidation, insertion, closedown and laid process, Wang ${ }^{[13]}$ prepared an EG with an initiation expansion temperature of $310^{\circ} \mathrm{C}$ and expansion volume of $270 \mathrm{~mL} / \mathrm{g}$.

Phosphorus-containing flame retardant ${ }^{15-17}$ is important flame retardants with good flame retardancy for its accelerating formation of charing layer and releasing $\mathrm{PO}$, which can catch free radical such as $\mathrm{H} \cdot, \mathrm{HO}$. and then stop combustion. In this research, $\mathrm{Na}_{4} \mathrm{P}_{2} \mathrm{O}_{7}$ is used as phosphorus-containing ancillary intercalation reagent in the intercalation reaction of graphite, through optimizing the dosage of oxidant $\mathrm{KMnO}_{4}$, intercalating reagent $\mathrm{H}_{2} \mathrm{SO}_{4}$, ancillary intercalation reagent $\mathrm{Na}_{4} \mathrm{P}_{2} \mathrm{O}_{7}$, reaction time and reaction temperature, to provide an suitable EG flame retardant or synergistic flame retardant for Linear Low-Density Polyethylene LLDPE possessing low machining temperature (less than $140{ }^{\circ} \mathrm{C}$ ) and burning temperature.

\section{MATERIALS AND METHOD}

\section{Instruments and materials}

SX3-4-13 Muffle furnace (Tientsin, precision of temperature $\pm 0.1 \%-0.4 \%$ ${ }^{\circ} \mathrm{C}$ ), 101-3 Oven (Shanghai, precision of temperature $\pm 2{ }^{\circ} \mathrm{C}$ ), Muller (Jiangsu), Instrument of limiting oxygen index LOI (Chengde), KYKY-2800B scanning electron microscope (Peking), Y-4Q X-ray diffractometer (Dandong), STA 449C TG/MS (Germany) and WCT-2 DTA (Shimadzu Japan) are used in this experiment.

Natural graphite $(\mathrm{C}, 5092)$ is provided by Action Carbon CO. LTD, Baoding. Acetic acid, $\mathrm{H}_{2} \mathrm{SO}_{4}(96 \%-98 \%), \mathrm{KMnO}_{4}$, Ammonium polyphosphate gls-APP(II) are all analytical reagents. LLDPE 7540 is purchased from Daqing.

\section{Preparation of $E G$}

First, the reactants are quantified according to a definite mass ratio of C: $\mathrm{KMnO}_{4}: \mathrm{H}_{2} \mathrm{SO}_{4}(98 \%): \mathrm{Na}_{4} \mathrm{P}_{2} \mathrm{O}_{7}$, and $\mathrm{H}_{2} \mathrm{SO}_{4}$ need to dilute to the required mass concentration. Then, under a constant temperature controlled with water bath, the quantified natural graphite is mixed with $\mathrm{H}_{2} \mathrm{SO}_{4}, \mathrm{KMnO}_{4}$ and $\mathrm{Na}_{4} \mathrm{P}_{2} \mathrm{O}_{7}$ in a $250 \mathrm{~mL}$ beaker, reaction lasts the required time. After reaction, the mixture is washed with de-ionized water and dipping $2.0 \mathrm{~h}$ until $\mathrm{pH}$ of waste-water reaches to $6.0 \sim 7.0$, then filtrated and dried at $50 \sim 60{ }^{\circ} \mathrm{C}$ for about $6 \mathrm{~h}, \mathrm{EG}$ products are gained.

\section{Character of $E G$}

\section{Detection of initiation expansion temperature}

$0.3000 \mathrm{~g}$ of the prepared EG is spread on evaporating dish, then the dish is placed in oven (when the controlled temperature is lower than $300{ }^{\circ} \mathrm{C}$ ) or Muffle furnace (when the temperature is higher than $300{ }^{\circ} \mathrm{C}$ ), which has been set as a constant temperature. After a definite time, take the sample out and measure its volume with a $5.0 \mathrm{~mL}$ graduated flask. In experiment, the temperature corresponding to 1.5 times of EGs' initiation volume is defined as EGs' initiation expansion temperature.

\section{Detection of expansion volume}

$\mathrm{EV}$ is an important factor to judge of the anti-flame properties. Ten EG samples with the mass of $0.3000 \mathrm{~g}$ are prepared, and they are heated at 100 ${ }^{\circ} \mathrm{C}, 200{ }^{\circ} \mathrm{C}, 300{ }^{\circ} \mathrm{C}, 400{ }^{\circ} \mathrm{C}, 500{ }^{\circ} \mathrm{C}, 600{ }^{\circ} \mathrm{C}, 700{ }^{\circ} \mathrm{C}, 800{ }^{\circ} \mathrm{C}, 900{ }^{\circ} \mathrm{C}, 1000$ ${ }^{\circ} \mathrm{C}$, respectively, then the volume is detected. Expansion time corresponding to different expansion temperature is listed in Table 1, and the higher the expansion temperature is, the shorter expansion time is selected. Curve of EV versus expansion temperature can be draw according to the experimental results. Temperature corresponding to intersection of the curvilinear tangent with temperature axis is treated as EG' initiation expansion temperature. The results are almost the same as the temperature corresponding to 1.5 times of EG initiation volume. 
Table 1. Expansion time used corresponding to different expansion temperature.

\begin{tabular}{|c|c|c|c|c|c|c|c|c|c|c|}
\hline $\mathrm{T} /{ }^{\circ} \mathrm{C}$ & 100 & 200 & 300 & 400 & 500 & 600 & 700 & 800 & 900 & 1000 \\
\hline Expansion time & $30 \mathrm{Min}$ & $30 \mathrm{Min}$ & $5 \mathrm{Min}$ & $1 \mathrm{Min}$ & $12 \mathrm{~S}$ & $12 \mathrm{~S}$ & $12 \mathrm{~S}$ & $5 \mathrm{~S}$ & $5 \mathrm{~S}$ & $5 \mathrm{~S}$ \\
\hline
\end{tabular}

\section{$X$-ray diffraction}

The X-ray diffraction spectra were recorded with an Y-4Q X-ray spectrometer using the $\mathrm{Cu} \mathrm{K \alpha}{ }_{1,2}$ radiation in the range $5^{\circ}<2 \theta<70^{\circ}$.

Measurement of EG flame retardancy

As flame retardant, a definite quantity of EG is added into LLDPE. After mix, extrusion, press and chop into sliver at $140{ }^{\circ} \mathrm{C}$ and $10 \mathrm{MPa}$, the slivers are used to measure anti-flame properties.

Detection of LOI

LOI is detected according to Standard of GB/T2406-1993 with oxygen index instrument.

Thermal Gravimetric TG analysis

Under $\mathrm{N}_{2}$ ambience with a flux of $25 \mathrm{~mL} / \mathrm{min}, 10 \mathrm{mg}$ of the detected sample is laid in porcelain crucible, and then it is heated to $800{ }^{\circ} \mathrm{C}$ at a heating rate of $10^{\circ} \mathrm{C} / \mathrm{min}$. Changes of sample weight with temperature are recorded.

\section{Differential thermal analysis DTA}

DTA is carried under atmosphere ambience with a flux of $60 \mathrm{~mL} / \mathrm{min}$. $\mathrm{Al}_{2} \mathrm{O}_{3}$ is used as reference compound, and heating rate of $5,10,15,20^{\circ} \mathrm{C} / \mathrm{min}$ are used.

\section{RESULTS AND DISCUSSION}

According to the former research ${ }^{18,19}$, influence of mass ratio of graphite to $\mathrm{KMnO}_{4}, \mathrm{Na}_{4} \mathrm{P}_{2} \mathrm{O}_{7}, \mathrm{H}_{2} \mathrm{SO}_{4}$ and its concentration, reaction time and reaction temperature on EG characteristics of initiation expansion temperature and $\mathrm{EV}$ are tested and discussed.

Influence of $\mathrm{KMnO}_{4}$ dosage on $\mathrm{EG}$ characteristics

In the range of $0.2 \sim 0.6 \mathrm{~g} / \mathrm{g}$, the influence of $\mathrm{KMnO}_{4}$ dosage is detected at the mass ratio of $\mathrm{C}: \mathrm{H}_{2} \mathrm{SO}_{4}(98 \%): \mathrm{Na}_{2} \mathrm{P}_{2} \mathrm{O}_{7}=1.0: 5.0: 0.6(\mathrm{~g} / \mathrm{g})$ at $40{ }^{\circ} \mathrm{C}$ reacting for $1.0 \mathrm{~h}$, and $\mathrm{H}_{2} \mathrm{SO}_{4}$ should be diluted to the mass concentration of $80 \%$ before reaction. Results showed in Figure 1 illustrate that when the mass ratio of $\mathrm{KMnO}_{4}$ to $\mathrm{C}$ is controlled as $0.4: 1.0$, the prepared EG possessing lower initiation expansion temperature of $160^{\circ} \mathrm{C}$ and maximum EV of $550 \mathrm{~mL} / \mathrm{g}$. Insufficiency $\mathrm{KMnO}_{4}$ would cause a incomplete oxygenation of graphite and decrease of product EV; Superfluous $\mathrm{KMnO}_{4}$ would cause excessive oxygenation of graphite, it could lead to decrease of EG granularity and then reduce $\mathrm{EV}$. In the tested dosage, increase of $\mathrm{KMnO}_{4}$ would cause the increase of initiation expansion temperature. The feasible dosage of $\mathrm{KMnO}_{4}$ can be set as $0.4 \mathrm{~g} / \mathrm{g}$.

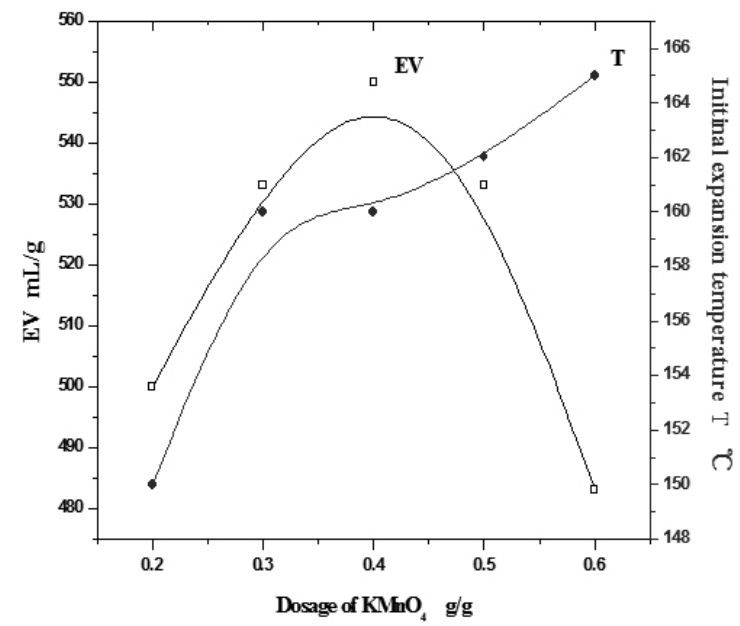

Figure 1. Influence of $\mathrm{KMnO}_{4}$ dosage on initiation expansion temperature and EV.

\section{Influence of $\mathrm{H}_{2} \mathrm{SO}_{4}$ dosage on EG characteristics}

In the range of $3.0 \sim 6.0 \mathrm{~g} / \mathrm{g}$, the influence of $\mathrm{H}_{2} \mathrm{SO}_{4}$ dosage with a mass concentration of $98 \%$ is detected at the mass ratio of $\mathrm{C}: \mathrm{KMnO}_{4}: \mathrm{Na}_{4} \mathrm{P}_{2} \mathrm{O}_{7}=$ 1.0:0.4:0.6 (g/g) at $40{ }^{\circ} \mathrm{C}$ reacting for $1.0 \mathrm{~h}$, and $\mathrm{H}_{2} \mathrm{SO}_{4}$ is diluted to the mass concentration of $80 \%$ before reaction. Results showed in Figure 2 illustrate that when the mass ratio of $\mathrm{H}_{2} \mathrm{SO}_{4}$ to $\mathrm{C}$ is controlled as 5.0:1.0, we can get EG with lowest initiation expansion temperature of $165^{\circ} \mathrm{C}$ and maximum EV of $550 \mathrm{~mL} / \mathrm{g}$. Insufficiency $\mathrm{H}_{2} \mathrm{SO}_{4}$ would cause a incomplete intercalation reaction and leading to the decrease of dilatability; Superfluous $\mathrm{H}_{2} \mathrm{SO}_{4}$ would cause the relative scarcity of $\mathrm{KMnO}_{4}$ and incomplete oxygenation of graphite. In the tested dosage, increase of $\mathrm{H}_{2} \mathrm{SO}_{4}$ can cause $\mathrm{V}$ type changes of initiation expansion temperature; lowest initiation expansion temperature of $165^{\circ} \mathrm{C}$ can be gained when EG possessing maximum expansion volume. The feasible dosage of $\mathrm{H}_{2} \mathrm{SO}_{4}$ can be set as $5.0 \mathrm{~g} / \mathrm{g}$.

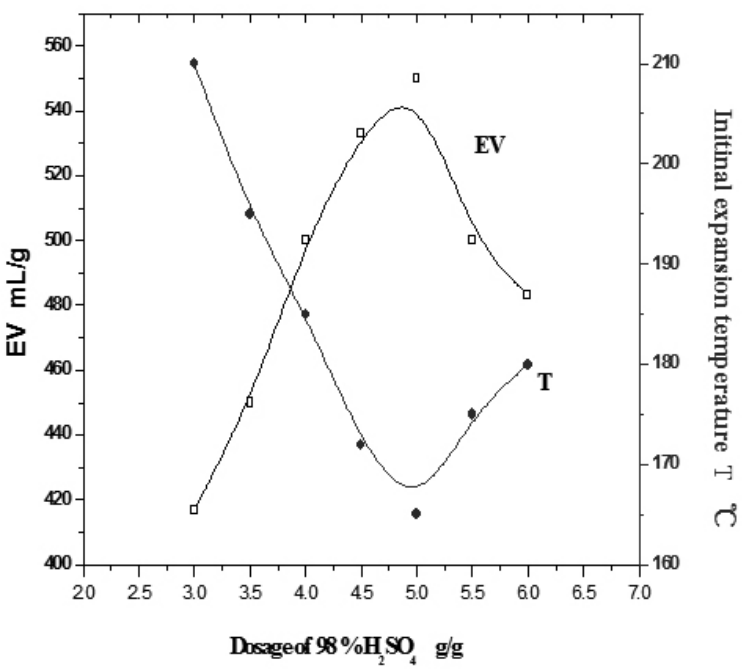

Figure 2. Influence of $\mathrm{H}_{2} \mathrm{SO}_{4}$ dosage on initiation expansion temperature and EV.

\section{Influence of $\mathrm{H}_{2} \mathrm{SO}_{4}$ concentration on $\mathrm{EG}$ characteristics}

By fixing the mass ratio of $\mathrm{C}: \mathrm{KMnO}_{4}: \mathrm{H}_{2} \mathrm{SO}_{4}(98 \%): \mathrm{Na}_{4} \mathrm{P}_{2} \mathrm{O}_{7}$ at 1.0:0.4:5.0:0.6 (g/g) and reacting for $1.0 \mathrm{~h}$ at $40{ }^{\circ} \mathrm{C}$, influence of $\mathrm{H}_{2} \mathrm{SO}_{4}$ mass concentration in the reaction is detected. Before reaction, it is diluted with de-ionized water to the mass concentration of $65 \%, 70 \%, 75 \%, 80 \%, 85 \%$, respectively. Results showed in Figure 3 illustrate that EV increases with the increase of $\mathrm{H}_{2} \mathrm{SO}_{4}$ concentration when it is controlled at lower value. When it reaches to $80 \%$, we can get EG with lowest initiation expansion temperature of $165^{\circ} \mathrm{C}$ and maximum EV of $550 \mathrm{~mL} / \mathrm{g}$. Too high $\mathrm{H}_{2} \mathrm{SO}$ concentration would cause an excessive oxygenation of graphite, and it lead to decrease of EV and increase of initiation expansion temperature. Feasible mass concentration of $\mathrm{H}_{2} \mathrm{SO}_{4}$ can be set as $80 \%$.

\section{Influence of $\mathrm{Na} \mathrm{P}_{2} \mathrm{O}_{7}$ dosage on $\mathrm{EG}$ characteristics}

In the range of $0.2 \sim 0.8 \mathrm{~g} / \mathrm{g}$, the influence of $\mathrm{Na}_{4} \mathrm{P}_{2} \mathrm{O}_{7}$ dosage is detected at the mass ratio of $\mathrm{C}: \mathrm{KMnO}: \mathrm{H}_{2} \mathrm{SO}(98 \%)=1.0: 0.4: 5.0(\mathrm{~g} / \mathrm{g})$ at $40{ }^{\circ} \mathrm{C}$ reacting for $1.0 \mathrm{~h}$, and $\mathrm{H}_{2} \mathrm{SO}_{4}$ is diluted to the mass concentration of $80 \%$ before reaction. As an ancillary intercalation reagent, increase of $\mathrm{Na}_{4} \mathrm{P}_{2} \mathrm{O}_{7}$ dosage can improve EG dilatability and reduce initiation expansion temperature as showed in Figure 4. When the mass ratio of $\mathrm{Na}_{4} \mathrm{P}_{2} \mathrm{O}_{7}$ to $\mathrm{C}$ is controlled as 0.6:1.0, we can get EG with initiation expansion temperature of $160{ }^{\circ} \mathrm{C}$ and $\mathrm{EV}$ of 550 $\mathrm{mL} / \mathrm{g}$. Superfluous $\mathrm{Na}_{4} \mathrm{P}_{2} \mathrm{O}_{7}$ would cause the relative scarcity of $\mathrm{KMnO}_{4}$ and incomplete oxygenation of graphite. The feasible dosage of $\mathrm{Na}_{4} \mathrm{P}_{2} \mathrm{O}_{7}$ can be set as $0.6 \mathrm{~g} / \mathrm{g}$. 


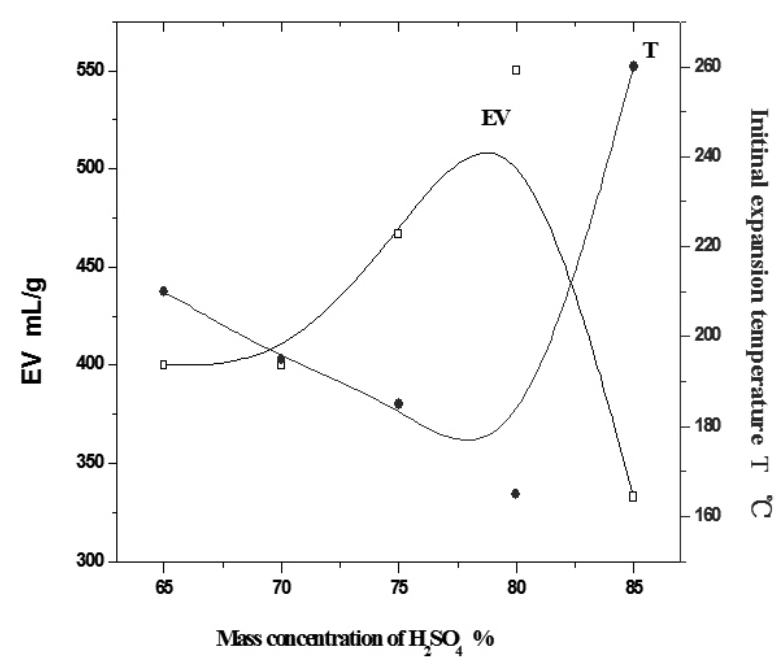

Figure 3. Influence of $\mathrm{H}_{2} \mathrm{SO}_{4}$ mass concentration on initiation expansion temperature and $\mathrm{EV}$.

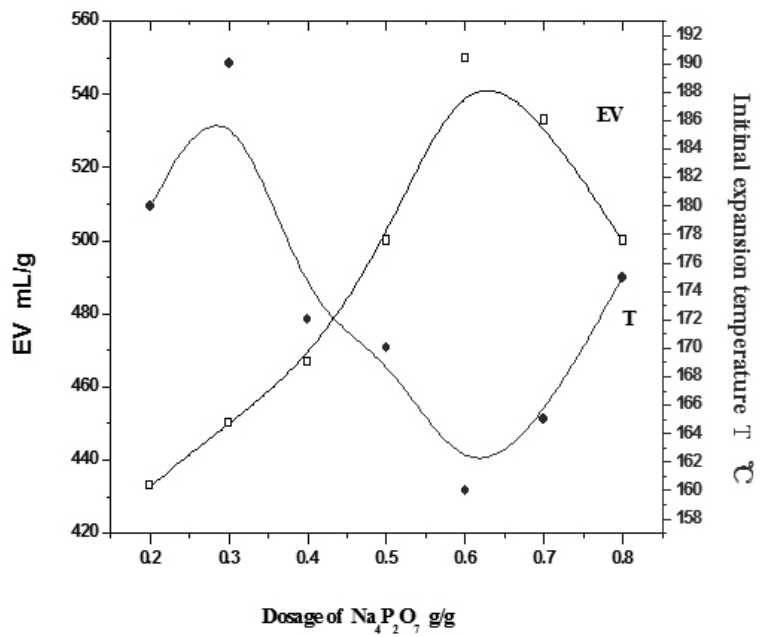

Figure 4. Influence of $\mathrm{Na}_{4} \mathrm{P}_{2} \mathrm{O}_{7}$ dosage on initiation expansion temperature and EV.

\section{Influence of reaction time on EG characteristics}

By fixing the mass ratio of $\mathrm{C}: \mathrm{KMnO}_{4}: \mathrm{H}_{2} \mathrm{SO}_{4}(98 \%): \mathrm{Na}_{4} \mathrm{P}_{2} \mathrm{O}_{7}$ at 1.0:0.4:5.0:0.6 (g/g), $\mathrm{H}_{2} \mathrm{SO}_{4}$ is diluted to $80 \%$, and reaction temperature controlled at $40{ }^{\circ} \mathrm{C}$, influence of reaction time on initiation expansion temperature and EV is detected. The increase of time can improve EG dilatability before the former $40 \mathrm{~min}$ as showed in Figure 5, and then its influence on initiation expansion temperature and EV can be ignored. The feasible reaction time can be set as $40 \mathrm{~min}$.

\section{Influence of reaction temperature on EG characteristics}

By fixing the mass ratio of $\mathrm{C}: \mathrm{KMnO}_{4}: \mathrm{H}_{2} \mathrm{SO}_{4}(98 \%): \mathrm{Na}_{4} \mathrm{P}_{2} \mathrm{O}_{7}$ at 1.0:0.4:5.0:0.6 (g/g), $\mathrm{H}_{2} \mathrm{SO}_{4}$ is diluted to $80 \%$, and reacting $40 \mathrm{~min}$, influence of reaction temperature on initiation expansion temperature and $\mathrm{EV}$ is detected. When it is less than $40{ }^{\circ} \mathrm{C}$, the increase of temperature can improve EG dilatability as showed in Figure 6. While, too high temperature can lead to tempestuously exothermic reaction and excessive oxygenation of graphite. So the feasible reaction temperature can be set as $40^{\circ} \mathrm{C}$.

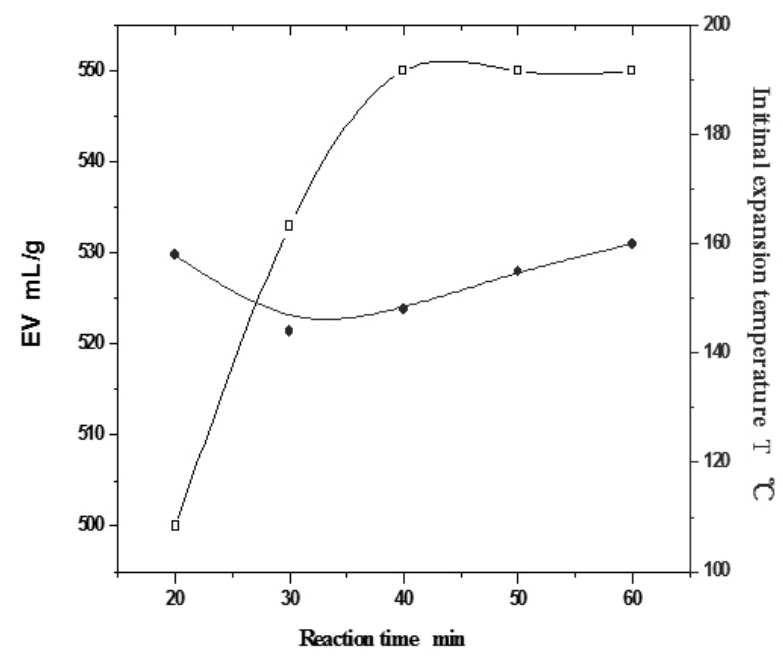

Figure 5. Influence of reaction time on initiation expansion temperature and EV.

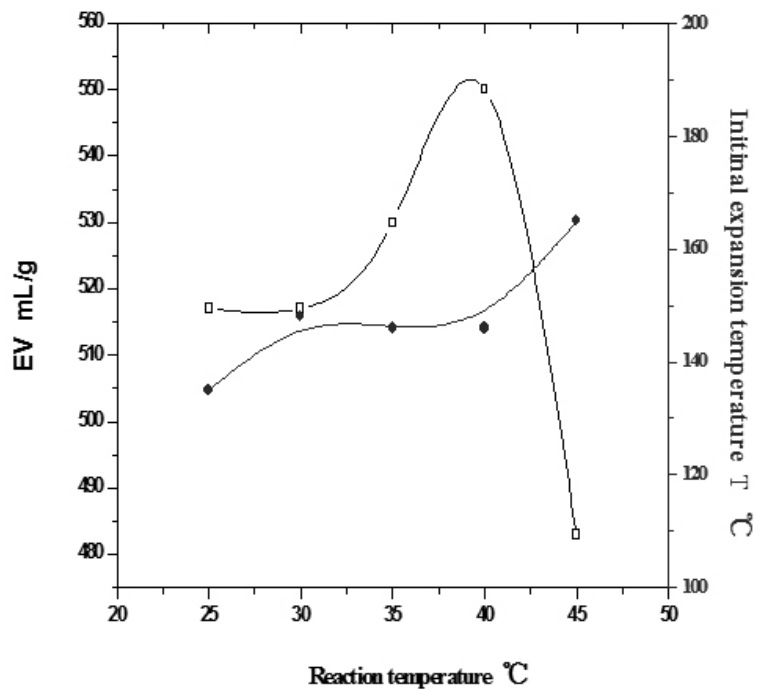

Figure 6. Influence of reaction temperature on initiation expansion temperature and $\mathrm{EV}$.

\section{Feasible condition to prepare EG}

According to the experiment results, feasible conditions to prepare $\mathrm{EG}$ are: mass ratio of C: $\mathrm{KMnO}_{4}: \mathrm{H}_{2} \mathrm{SO}_{4}(98 \%): \mathrm{Na}_{4} \mathrm{P}_{2} \mathrm{O}_{7}=1.0: 0.4: 5.0: 0.6\left(\mathrm{H}_{2} \mathrm{SO}_{4}\right.$ diluted to mass concentration of $80 \%$ before intercalation reaction), the reaction time is $40 \mathrm{~min}$ at $40{ }^{\circ} \mathrm{C}$. initiation expansion temperature and $\mathrm{EV}$ of the prepared EG are $148 \pm 2{ }^{\circ} \mathrm{C}$ and $550 \mathrm{~mL} / \mathrm{g}$, respectively. Expansion curve of the gained EG is detected as Figure 7. EV can reach $267 \mathrm{~mL} / \mathrm{g}$ at $400{ }^{\circ} \mathrm{C}$, and the maximum $\mathrm{EV}$ of $550 \mathrm{~mL} / \mathrm{g}$ get at $800^{\circ} \mathrm{C}$.

Preparation of EG, with no assistant inserting reagent $\mathrm{Na} P \mathrm{P}_{2} \mathrm{O}$

$\mathrm{EG}$ is prepared under the condition of $\mathrm{C}: \mathrm{KMnO}_{4}: \mathrm{H}_{2} \mathrm{SO}_{4}(98 \%)=1.0: 0.4: 5.0$ for $40 \mathrm{~min}$ at $40{ }^{\circ} \mathrm{C}$ and $\mathrm{H}_{2} \mathrm{SO}_{4}$ diluted to mass concentration of $80 \%$, no $\mathrm{Na}_{4} \mathrm{P}_{2} \mathrm{O}_{7}$ is added during reaction. $\mathrm{EV}$ of $\mathrm{EG}_{1}$ is detected as $330 \mathrm{~mL} / \mathrm{g}$.

\section{$X R D$ analysis of $E G$}

XRD Analysis results for material graphite and the EG are showed in Figure 8. The two diffraction peaks of $3.34 \AA$ and $1.67 \AA$ are the characteristic spectrum of material graphite. Because it has the plane structure of samdwich, the peak of $3.34 \AA$ is strengthened during XRD detection. In the XRD analysis of EG, the characteristic peak of $3.34 \AA$ is replaced with a new peak of $3.39 \AA$. The displacement of diffraction peak to big angle show the layer space is bigger than the material graphite, and new substance has inserted into samdwich of graphite. 


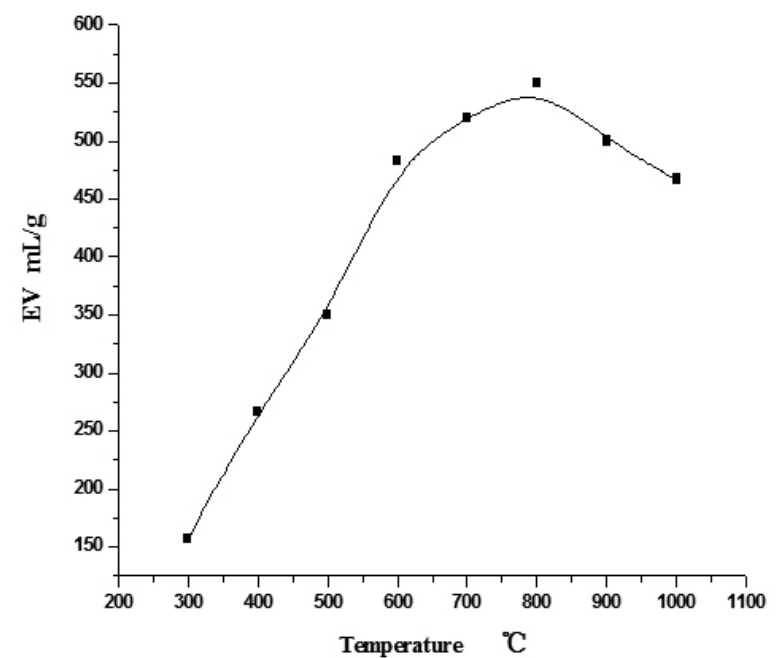

Figure 7. Expansion curve of EG.

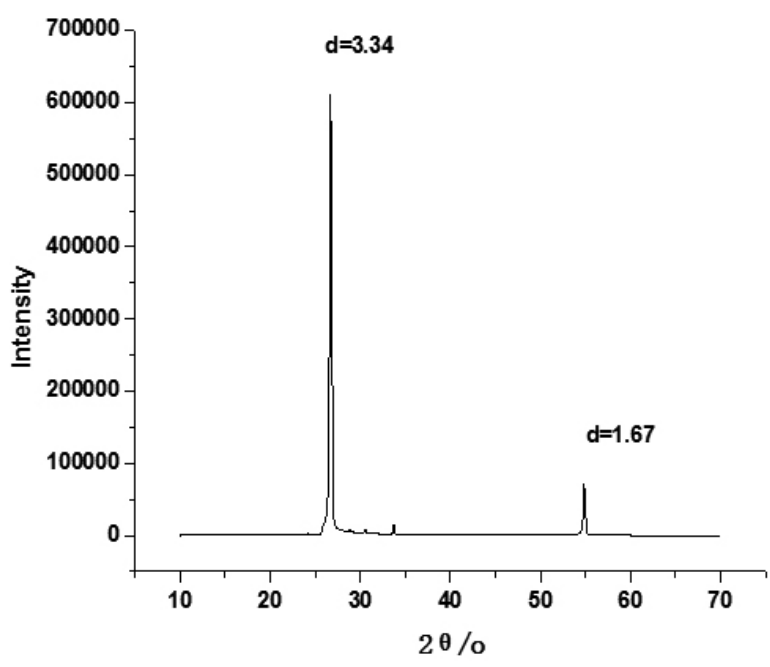

(a) Material graphite

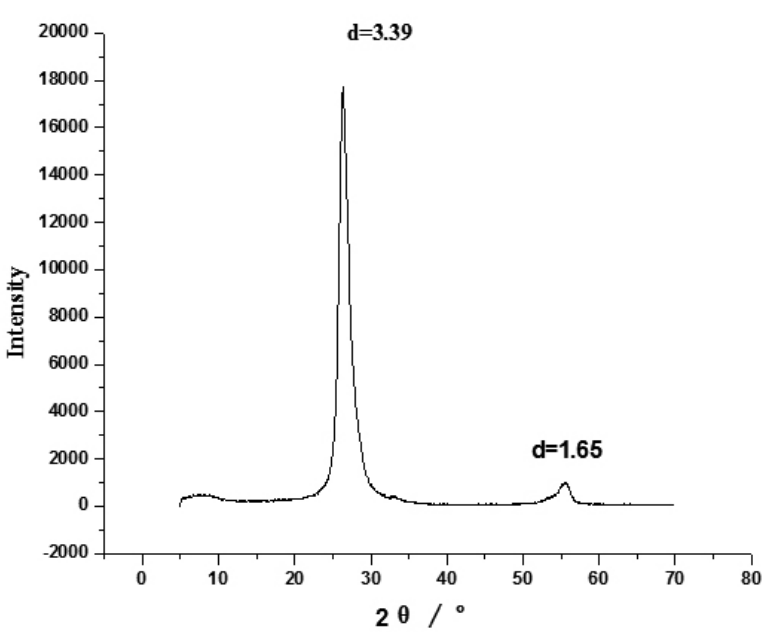

(b) EG

Figure 8. XRD of material graphite and the EG.
The anti-flame capability of EG for LLDPE

LLDPE is kinds of plastic with characteristics of flammability and low processing temperature less than $140{ }^{\circ} \mathrm{C}$. So we can select the prepared EG as flame retardant. Flame retardants are added to LLDPE according to the proportion listed in Table 2. After mixing, pressing into piece and cutting into strip, the LOC is detected and the results are listed in Table 2. The addition of $30 \%$ EG can improve LOC up to $29.4 \%$. But the addition of the same amount of EG $\mathrm{F}_{1}$ or purchase EG to LLDPE can only get a LOC of $26.8 \%$ and $23 \%{ }^{20}$, respectively. So the addition of assistant inserting reagent $\mathrm{Na}_{4} \mathrm{P}_{2} \mathrm{O}_{7}$ can improve EG dilatability and flame retardancy. LOC is only $19.8 \%$ with single $30 \%$ APP (II) as flame retardant, and the addition of $20 \%$ EG together with $10 \%$ APP (II) can improve LOC to $31.2 \%$, it show the synergistic anti-flame of EG with APP (II). After combustion of the anti- flame LLDPE, EG changes to graphite worm on the surface of LLDPE (Figure 9), and the swollen multicellular char can limit heat and mass transfer, as well as oxygen diffusion, thus interrupting the self-sustained combustion of LLDPE.

Table 2. Results of LOI.

\begin{tabular}{|c|c|c|c|c|}
\hline LLDPE/\% & $\mathrm{EG} / \%$ & $\mathrm{EG}_{1} / \%$ & $\mathrm{APP}(\mathrm{II}) / \%$ & $\mathrm{LOI} / \%$ \\
\hline 100 & 0 & 0 & 0 & 17.5 \\
\hline 70 & 0 & 0 & 30 & 19.8 \\
\hline 70 & 10 & 0 & 20 & 25.5 \\
\hline 70 & 20 & 0 & 10 & 31.2 \\
\hline 70 & 30 & 0 & 0 & 29.4 \\
\hline 70 & 0 & 30 & 0 & 26.8 \\
\hline
\end{tabular}

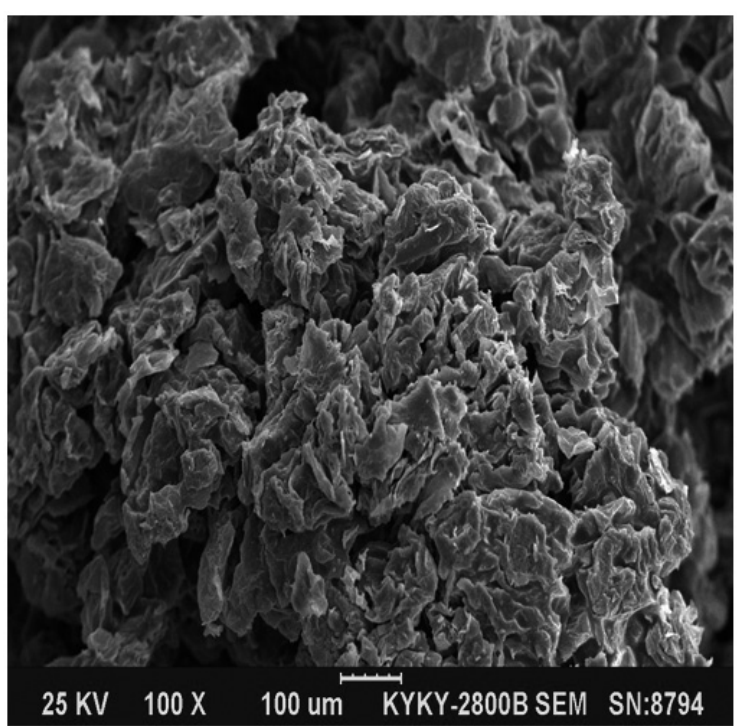

Figure 9. The SEM of $70 \%$ LLDPE $/ 10 \% \mathrm{APP}(\mathrm{II}) / 20 \% \mathrm{EG}$ after combustion.

\section{TG analysis}

TG analysis results for samples of 70\%LLDPE $/ 10 \% \mathrm{APP}(\mathrm{II}) / 20 \% \mathrm{EG}$ and $70 \%$ LLDPE $/ 30 \% \mathrm{EG}$ are showed as Figure 10 . Mass loss of these anti-flame systems among $100 \sim 400{ }^{\circ} \mathrm{C}$ is less than $5 \%$, which is caused by incomplete decomposition of APP(II) and expansion of EG. The loss of weight is near to $10 \%$ when temperature increases to $450{ }^{\circ} \mathrm{C}$. $60 \%$ of loss of weight occurs among $450 \sim 520^{\circ} \mathrm{C}, \mathrm{EG}$ already shows high dilatability under this temperature (showed as Figure 7). Compare $70 \%$ LLDPE $/ 10 \%$ APP(II) $/ 20 \%$ EG sample to $70 \%$ LLDPE $/ 30 \% \mathrm{EG}$ sample, the former give higher residual carbon of $25 \%$ than the latter of $19 \%$, that testify the synergistic anti-flame of EG with APP (II). 


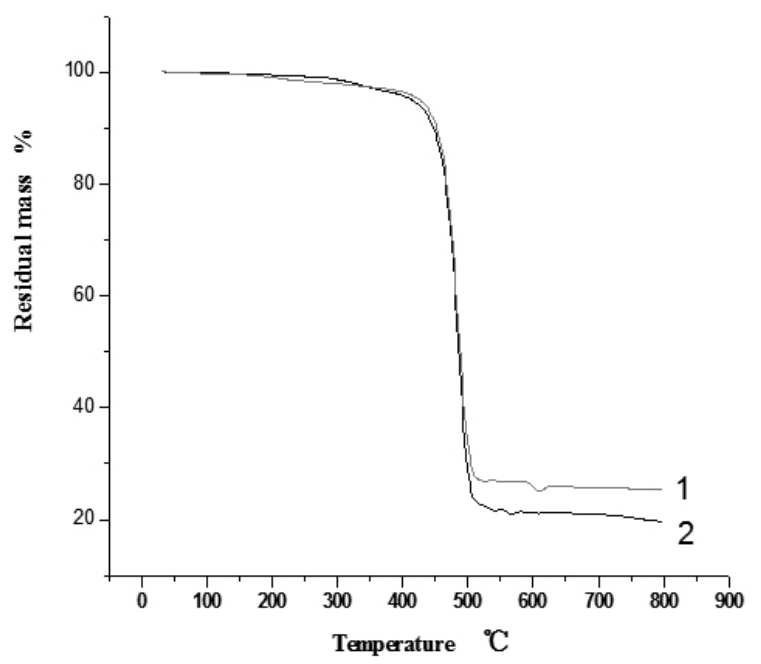

Figure 10. TG of $70 \%$ LLDPE $/ 10 \% \mathrm{APP} / 20 \% \mathrm{EG}$ and $70 \% \mathrm{LLDPE} / 30 \% \mathrm{EG}$ $\begin{array}{ll}\text { 1. } 70 \% \mathrm{LLDPE} / 10 \% \mathrm{APP} / 20 \% \mathrm{EG} & 2.70 \% \text {. }\end{array}$

\section{DTA analysis}

During decomposition of $\mathrm{APP}(\mathrm{II})$ and expansion of EG, they will consume huge heat, and then reduce material temperature. Compare $70 \%$ LLDPE $/ 10 \%$ APP(II) $/ 20 \%$ EG sample to $70 \%$ LLDPE $/ 30 \%$ EG sample showed as Figure 11, the former give lower surface temperature, especially in the range of $100 \sim 300{ }^{\circ} \mathrm{C}$, , and it is much more fit for the flame retardancy in fire early stage. During the expansion of EG, the existing and decomposing of APP(II) might cause compacter multicellular char, which can limit heat and mass transfer, then retard combustion.

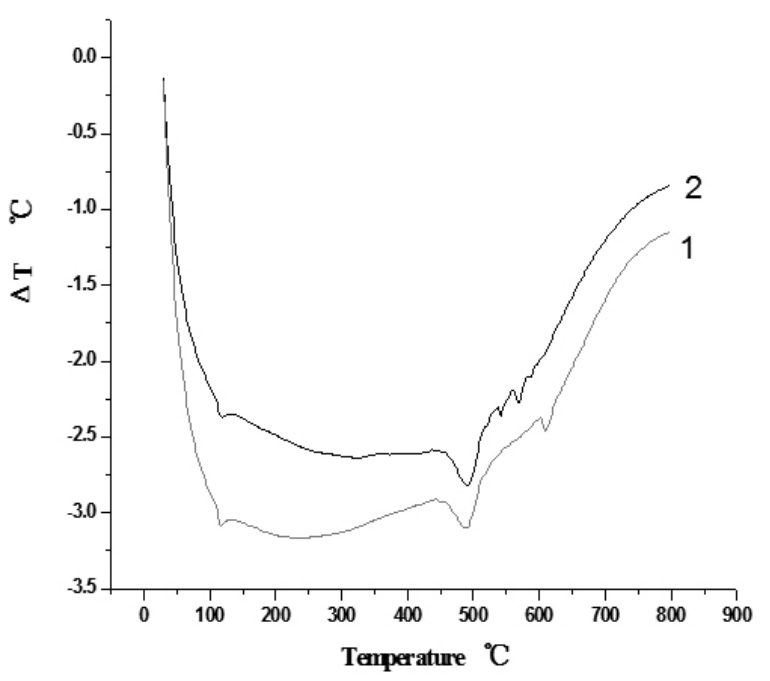

Figure 11. DTA of $70 \% \mathrm{LLDPE} / 10 \% \mathrm{APP} / 20 \% \mathrm{EG}$ and $70 \%$ LLDPE $/ 30 \%$ EG

1. $70 \%$ LLDPE $/ 10 \% \mathrm{APP} / 20 \% \mathrm{EG} \quad 2.70 \% \mathrm{LLDPE} / 30 \% \mathrm{EG}$.

\section{Analysis of anti-flame mechanism}

Combine experiment data and TG DTA results, we can deduce that: When EG exposes to flame, it gives a swollen multicellular char, which limits heat and mass transfer, as well as oxygen diffusion. Instantaneous expansion of EG can absorbs huge heat and releases $\mathrm{CO}_{2}$; Coexistence of EG and APP(II) can give more residual carbon and induce lower surface temperature, that cause an effect of synergistic flame retardancy.

\section{CONCLUSIONS}

Adjustment of $\mathrm{KMnO}_{4}, \mathrm{H}_{2} \mathrm{SO}_{4}$ and $\mathrm{Na}_{4} \mathrm{P}_{2} \mathrm{O}_{7}$ dosages can influence EGs' initiation expansion temperature and $\mathrm{EV}$. The feasible condition to get $\mathrm{EG}$ with low initiation expansion temperature and high $\mathrm{EV}$ is: C: $\mathrm{KMnO}_{4}: \mathrm{H}_{2} \mathrm{SO}_{4}(98 \%): \mathrm{Na}_{4} \mathrm{P}_{2} \mathrm{O}_{7}=1.0: 0.4: 5.0: 0.6$ (mass ratio), the reaction lasts $40 \mathrm{~min}$ at $40^{\circ} \mathrm{C}$, and $\mathrm{H}_{2} \mathrm{SO}_{4}$ need to be diluted to a mass concentration of $80 \%$. Under this condition, EG with an initiation expansion temperature of 148 $\pm 2{ }^{\circ} \mathrm{C}$ and expansion volume of $550 \mathrm{~mL} / \mathrm{g}$ can be gained.

EG possess well anti-flame capability for its absorbing huge heat and expansion giving birth to swollen multicellular char, which acts as physical barrier for heat and mass transfer. Addition of 30\% EG to LLDPE can improve LOI up to $29.4 \%$ from $17.5 \%$. Addition of $20 \%$ EG to LLDPE together with $10 \%$ APP (II) can improve LOI up to $31.2 \%$. There is synergistic flame retardancy between EG and APP(II).

\section{ACKNOWLEDGEMENTS}

This study was supported Doctor Foundation of Hebei province Education Office (China, No.B2004402). We gratefully acknowledge their support during the study.

\section{REFERENCES}

1. S. Zhang and A.R. Horrocks, Prog. Polym. Sci., 281517 (2003).

2. H.Y. Tang, J.Y. Chen and Y.H. Guo, Mater. Design, 313525 (2010).

3. M. Alaee, P. Arias, A. Sjodin and A. Bergman, Environ. Int., 29683 (2003).

4. I. Watanabe and S.I. Sakai, Environ. Int., 29665 (2003).

5. J.Z. Su, A.K. Kim and M. Kanabus-Kaminska, Fire Safety J., 311 (1998).

6. C.S. Chou, S.H. Lin and C.I. Wang, Adv. Powder Technol., 20169 (2009)

7. J.W. Gu, G.C. Zhang, S.L. Dong, Q.Y. Zhang and J. Kong, Surf. Coatings Technol., 2017835 (2007).

8. W.B. Gan and X.B. Zeng, J. Wuhan Univ. Technol., 1455 (1992).

9. X.L. Chen, K.M. Song and J.H. Li, Chinese Carbon, 341599 (1996).

10. H. Zhao, W. Zhou, W.C. Shen, F.Y. Kang, Chinese Mater. Sci. Eng., 20 153 (2002).

11. H.F. Zhu, Q.L. Zhu, J. Li, K. Tao, L.X. Xue and Q. Yan, Polym. Degrad. Stabil., 96183 (2011).

12. S. Duquesne, M.L. Bras, S. Bourbigot, R. Delobel, H. Vezin, G. Camino, B. Eling, C. Lindsay and T. Roels, Fire Mater., 27103 (2003).

13. K.M. Song and L. Wang, Preparation of expandable graphite of high initiation expansion temperature, CN200610012936.1, 2006.

14. L. Wang, K.M. Song, S.H. Zhang, Q. Li, Y.P. Li and M. Liu, Bull. Chinese Ceram. Soc., 28844 (2009).

15. S. Horold, Polym. Degrad. Stabil., 64427 (1999).

16. P.L. Kuo, J.M. Chang and T. L. Wang, J. Appl. Polym. Sci., 691635 (1998).

17. L.L. Wei, D.Y. Wang, H.B. Chen, L. Chen, X.L. Wang and Y.Z. Wang, Polym. Degrad. Stabil., 961557 (2011).

18. X.Y. Pang, S.K. Zhi, Y.J. Su, L. Liu and F. Lin, J. Hebei Univ. (Nat. Sci.), 31497 (2011).

19. G.Q. Xi, X.Y. Pang, J.S. Wang and Y.J. Su, Chinese Non-miner., 3418 (2011).

20. A.H. Yan, Z.Q. Zhou and Z. Wu, Chinese Chem. Engineer, 348 (2006). 